\title{
Resíduo do processo Kraft (dregs) como matéria-prima alternativa para cerâmica vermelha
}

\section{(Kraft process waste (dregs) as alternative raw material for red ceramic)}

\author{
L. R. Rodrigues ${ }^{1 *}$, E. R. Rodrigues ${ }^{1}$, C. B. Albani $^{1}$, A. S. dos Reis ${ }^{1}$, D. M. Louzada ${ }^{1}$, V. P. Della Sagrillo ${ }^{1}$ \\ ${ }^{I}$ Instituto Federal do Espírito Santo, Av. Vitória 1729, 29040-780, Vitória, ES, Brasil
}

\begin{abstract}
Resumo
Neste trabalho foi avaliada a utilização de dregs, um resíduo sólido inorgânico proveniente do processo Kraft, como matéria-prima alternativa em cerâmica vermelha. As matérias-primas foram caracterizadas por fluorescência de raios $X$, difração de raios X, distribuição de tamanho de partículas, análise térmica diferencial e termogravimétrica. Os corpos de prova com adições de até $40 \%$ em massa do resíduo foram conformados por prensagem uniaxial e sinterizados a 850 e $950{ }^{\circ} \mathrm{C}$, sendo então determinadas as seguintes propriedades físico-mecânicas: resistência à flexão, retração linear, absorção de água, porosidade aparente, massa específica aparente e perda ao fogo. Também foi feita análise das fases desenvolvidas durante a sinterização e da microestrutura final por difração de raios X e microscopia eletrônica de varredura, respectivamente. Os resultados mostraram que a incorporação de até $20 \%$ em massa de dregs não interferiu na resistência à flexão da massa, sendo possível sua utilização em substituição parcial da argila.
\end{abstract}

Palavras-chave: cerâmica vermelha, resíduos industriais, dregs.

\begin{abstract}
In this paper the use of dregs, an inorganic solid waste generated by Kraft process, as an alternative raw material in red ceramic was evaluated. The raw materials, dregs and clay, were characterized by X-ray fluorescence, X-ray diffraction, particle size distribution by laser diffraction, differential thermal analysis and thermogravimetry. Formulations with varying dregs content between 0 and $40 \mathrm{wt} \%$ were prepared. The plasticity of mixtures was evaluated by Atterberg method. Specimens were obtained by uniaxial pressing and fired at 850 and $950{ }^{\circ} \mathrm{C}$, then the following physicalmechanical properties were determined: flexural strength, firing shrinkage, water absorption, open porosity, bulk density and loss on ignition. Crystalline phases developed during sintering and final microstructure were evaluated by $X$-ray diffraction and scanning electron microscopy, respectively. The results showed that incorporation of dregs until 20 wt \% did not affect flexural strength, being possible its use in partial replacement of clay.
\end{abstract}

Keywords: red ceramic, industrial wastes, dregs.

\section{INTRODUÇÃO}

O processo mais utilizado para a fabricação de polpa celulósica é o Kraft, o qual consiste na digestão da celulose com $\mathrm{NaOH}$ e $\mathrm{Na}_{2} \mathrm{~S}$, a fim de realizar a deslignificação da celulose, seguida da etapa de recuperação química dos reagentes (Fig. 1). As indústrias que utilizam o processo Kraft geram diversos resíduos sólidos, principalmente nesta última etapa, que se tornam um inconveniente devido aos custos com a disposição em aterros e impactos ambientais. Em função do emprego de cal para regeneração do $\mathrm{NaOH}$, os resíduos precipitados durante a recuperação dos reagentes têm como principal componente o $\mathrm{Ca}$, geralmente na forma

*lorena.raphael92@gmail.com

(D) https://orcid.org/0000-0002-7270-6040 de carbonato (calcita) ou hidróxido (portlandita) [1]. O dregs, um dos resíduos inorgânicos gerados na etapa de recuperação dos reagentes químicos do processo Kraft, é alcalino, essencialmente constituído de carbonatos, e em grande parte disposto em aterros [2]. Por ser o primeiro resíduo removido do sistema por sedimentação, é o que carrega mais componentes tóxicos, sendo de difícil utilização. Uma alternativa para o uso de resíduos inorgânicos do processo Kraft é o emprego como materiais para neutralização de solos e efluentes [3], em função de sua elevada concentração de $\mathrm{CaCO}_{3}$. Contudo, elevadas concentrações de dregs podem aumentar o teor de metais pesados, impossibilitando sua aplicação.

Como massas argilosas têm elevada capacidade de incorporação de resíduos sem que haja detrimento das propriedades tecnológicas do produto final, em países 
como o Brasil, que possuem grandes reservas de argila, a incorporação em cerâmica vermelha se mostra como uma boa alternativa para o reaproveitamento de resíduos industriais [4]. Ainda deve-se ressaltar que os processos de fabricação desse tipo de produto normalmente não necessitam de alterações significativas quando são adicionados resíduos às formulações [5]. A incorporação de resíduos sólidos industriais em cerâmica vermelha tem a vantagem de reduzir os danos ao meio ambiente e custos relacionados à disposição em aterros, bem como redução na extração de matéria-prima argilosa. Alguns estudos [6-8] já demonstraram a potencialidade da incorporação em massas argilosas de resíduos do processo Kraft. Já foi mostrado que a substituição de argila por 5 ou $10 \%$ de dregs permite a fabricação de tijolos com propriedades dentro das estabelecidas pelas normas brasileiras [6]. Em pesquisa para avaliar a possibilidade de formulações cerâmicas a partir de resíduos da indústria de celulose, foi verificado que, apesar de o material obtido ter sido leve e poroso, algumas composições atingiram resistência à flexão satisfatória para uso em produtos de cerâmica vermelha [7, 8]. Dessa forma, esse trabalho teve como objetivo avaliar a influência da incorporação de dregs em massas argilosas para fabricação de cerâmica vermelha.

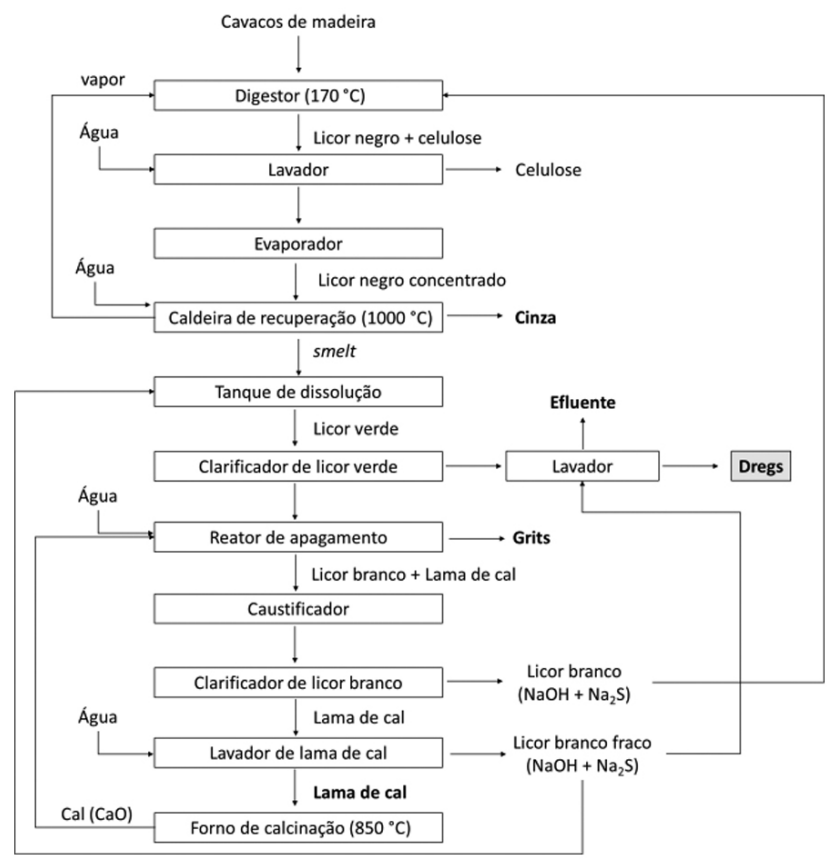

Figura 1: Esquema geral do processo Kraft, indicando os resíduos gerados (adaptada de [1]).

[Figure 1: General scheme of Kraft process, indicating wastes generated (adapted from [1]).]

\section{MATERIAIS E MÉTODOS}

Este trabalho utilizou como matérias-primas uma argila, extraída na cidade de Batinga, em MG, e utilizada por uma empresa da região de Colatina, ES, e um resíduo inorgânico, denominado dregs, gerado durante a etapa de recuperação química dos reagentes do processo Kraft (Fig. 1), proveniente de uma indústria de polpa de celulose localizada na Bahia. A caracterização das matérias-primas foi realizada por meio das técnicas descritas a seguir.

A composição química quantitativa foi determinada por espectrometria de fluorescência de raios X (FRX), em um equipamento PANalytical, AxiosMax, com tubo de $4 \mathrm{~kW}$ e alvo de ródio. Para esta análise, as matériasprimas foram moídas em moinho de ágata com almofariz/ pistilo motorizado MA590 Marconi, entre 20 e $30 \mathrm{~min}$, até serem obtidas partículas com tamanho inferior a $20 \mu \mathrm{m}$. Posteriormente foi feita homogeneização das amostras com tetraborato e nitrato de lítio e, em seguida, foi realizada fusão a $1000{ }^{\circ} \mathrm{C}$ para obter amostras na forma de pérolas com $40 \mathrm{~mm}$ de diâmetro utilizadas para determinação da composição. A análise mineralógica foi realizada por difração de raios X (DRX), em difratômetro Brucker, D8 Advance, utilizando radiação CuK $\alpha$ e intervalo de varredura de 10 a $75^{\circ}(2 \theta)$. Os difratogramas foram interpretados por meio do software DIFFRAC.EVA, utilizando os padrões fornecidos pela base de dados do ICDD-PDF. As amostras submetidas a esta análise foram secas em estufa a $110{ }^{\circ} \mathrm{C}$ durante $24 \mathrm{~h}$, desaglomeradas manualmente com almofariz e pistilo, e peneiradas até a fração passante na peneira 200 mesh. A distribuição de tamanho de partículas (DTP) foi determinada pela técnica de difratometria a laser, em equipamento Malvern Mastersize Hydro 2000UM, utilizando água destilada como meio dispersante. $\mathrm{O}$ comportamento térmico foi avaliado por meio de análise térmica diferencial/ termogravimétrica (ATD/TG), realizada em equipamento de análise térmica simultânea Netzsch STA 409 E, com ar sintético (fluxo de $10 \mathrm{~cm}^{3} / \mathrm{min}$ ) e taxa de aquecimento de $10{ }^{\circ} \mathrm{C} /$ min entre 20 e $1110{ }^{\circ} \mathrm{C}$. As análises de difratometria a laser e ATD/TG foram realizadas no resíduo e na argila in natura.

Para preparação das massas, as matérias-primas foram secas em estufa a $110{ }^{\circ} \mathrm{C}$ por $24 \mathrm{~h}$. Em seguida, o dregs e a argila foram desaglomerados manualmente com auxílio de almofariz e pistilo e peneirados até a fração passante na peneira de 60 mesh, tendo sido então preparadas formulações com $0,10,20,30$ e $40 \%$ em massa de dregs. A plasticidade das misturas foi avaliada pelo método de Atterberg de acordo com as normas brasileiras NBR 6459/1984 [9] e NBR 7180/1984 [10]. Os corpos de prova (CPs) com dimensões de $60 \times 20 \times 5 \mathrm{~mm}$ foram conformados por prensagem uniaxial em prensa hidráulica utilizando matriz de aço e pressão de $25 \mathrm{MPa}$. Para possibilitar a moldagem dos CPs, as massas preparadas foram umidificadas com $10 \%$ em massa de água. Após moldagem, os CPs foram secos em estufa a $110 \pm 5^{\circ} \mathrm{C}$ durante $24 \mathrm{~h}$. A queima dos CPs foi realizada em forno tipo mufla Fortelab ME 1700, em atmosfera oxidante, com taxa de aquecimento de $2{ }^{\circ} \mathrm{C} /$ min até as temperaturas máximas de queima de 850 e $950{ }^{\circ} \mathrm{C}$ e tempo de patamar de $180 \mathrm{~min}$. $\mathrm{O}$ resfriamento até a temperatura ambiente foi realizado por convecção natural, mantendo os CPs dentro do forno.

Após a queima, foram determinadas as seguintes 
propriedades físico-mecânicas dos CPs, de acordo com metodologia proposta em [11]: retração linear de queima, absorção de água, porosidade aparente, massa específica aparente, perda ao fogo e tensão de ruptura à flexão (3 pontos). Em cada ensaio foram utilizados seis corpos de prova de cada formulação. Para avaliar as fases formadas durante a queima, foi realizada análise mineralógica dos CPs sinterizados por DRX, seguindo o mesmo procedimento utilizado para análise das matérias-primas, porém para moagem dos CPs foi utilizado moinho de ágata com almofariz/pistilo motorizado MA590 Marconi. Também foi avaliada a variação morfológica com a adição de dregs por meio da análise da superfície de fratura dos CPs sinterizados por microscopia eletrônica de varredura (MEV) utilizando microscópio Zeiss EVO MA10.

\section{RESULTADOS E DISCUSSÃO}

Os resultados da análise química e perda ao fogo das matérias-primas são apresentados na Tabela I. A argila foi constituída essencialmente por $\mathrm{SiO}_{2}$ e $\mathrm{Al}_{2} \mathrm{O}_{3}$, além de elevado teor de $\mathrm{Fe}_{2} \mathrm{O}_{3}$, superior a 9\%, o qual promoveu cor vermelha aos corpos sinterizados. A baixa concentração de $\mathrm{CaO}$ indicou que essa argila possuiu baixo teor de carbonatos. A perda ao fogo da argila foi próxima à comumente observada em argilas para fabricação de cerâmica vermelha [12-14] e foi decorrente principalmente da perda de água de constituição do argilomineral, além da decomposição da matéria orgânica e de carbonatos. O dregs por sua vez foi constituído majoritariamente por $\mathrm{CaO}$, na forma de carbonato, como indicado na sua análise mineralógica (Fig. 2b), seguido dos óxidos $\mathrm{SiO}_{2}, \mathrm{Na}_{2} \mathrm{O}$ e

Tabela I - Composição química das matérias-primas (\% em massa).

[Table I - Chemical composition of raw materials (in wt\%).]

\begin{tabular}{ccc}
\hline Componente & Argila & Dregs \\
\hline $\mathrm{SiO}_{2}$ & 47,25 & 3,01 \\
$\mathrm{Al}_{2} \mathrm{O}_{3}$ & 28,52 & 0,71 \\
$\mathrm{Fe}_{2} \mathrm{O}_{3}$ & 9,07 & 0,45 \\
$\mathrm{TiO}_{2}$ & 1,25 & $<0,05$ \\
$\mathrm{~K}_{2} \mathrm{O}$ & 0,81 & 0,21 \\
$\mathrm{MgO}$ & 0,45 & 5,85 \\
$\mathrm{Na}_{2} \mathrm{O}$ & 0,11 & 8,34 \\
$\mathrm{CaO}$ & 0,10 & 32,60 \\
$\mathrm{P}_{2} \mathrm{O}_{5}$ & 0,08 & 0,51 \\
$\mathrm{MnO}$ & $<0,05$ & 0,29 \\
$\mathrm{Cr}_{2} \mathrm{O}_{3}$ & nd & 0,34 \\
$\mathrm{SrO}$ & nd & 0,16 \\
$\mathrm{SO}_{3}$ & nd & 4,53 \\
$\mathrm{Perda}$ ao fogo & 12,32 & 42,80 \\
\hline
\end{tabular}

nd - não detectado.
$\mathrm{MgO}$. Apesar de a composição química variar de acordo com a planta industrial, a análise realizada foi coerente com as reportadas $[1,7,15]$. Sua composição química indicou que a utilização em massas argilosas pode levar à redução da temperatura de queima por aumentar a concentração de óxidos fundentes, alcalinos e alcalinos terrosos, favorecendo a sinterização. Na faixa de temperatura em que é realizada a sinterização de cerâmica vermelha, óxidos de metais alcalinos e alcalinos terrosos contribuem para a densificação da peça [16]. Contudo, a alta perda ao fogo desse resíduo em torno de $43 \%$ é um ponto negativo para sua aplicação em cerâmicas sinterizadas, pois pode contribuir para aumento da porosidade. Na análise mineralógica da argila (Fig. 2a) notou-se que é uma argila caulinítica, com quartzo como principal impureza, que reduz a plasticidade da argila. No difratograma de raios $\mathrm{X}$ do resíduo (Fig. $2 \mathrm{~b}$ ) foi identificada apenas a fase calcita $\left(\mathrm{CaCO}_{3}\right)$, justificando sua perda ao fogo, a qual foi decorrente essencialmente da decomposição do carbonato.
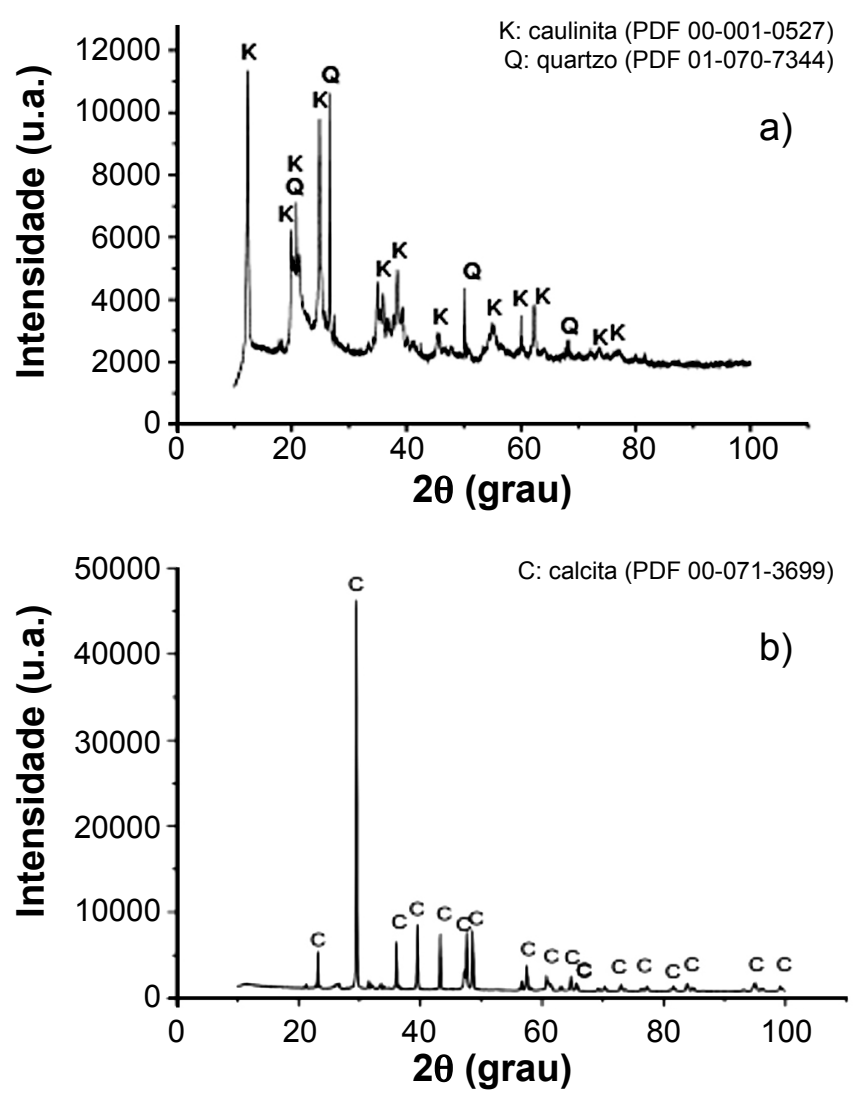

Figura 2: Difratogramas de raios X de: a) argila; e b) resíduo. [Figure 2: X-ray diffraction patterns of: a) clay; and b) waste.]

A distribuição de tamanho de partículas das matériasprimas é mostrada na Fig. 3. Observou-se que o resíduo apresentou granulometria mais grosseira do que a argila, com apenas $2 \%$ das partículas com diâmetro inferior a 2 $\mu \mathrm{m}$ ('fração argila'), $40 \%$ com diâmetro entre 2 e $20 \mu \mathrm{m}$ ('fração silte') e $58 \%$ com granulometria superior a $20 \mu \mathrm{m}$ 
('fração areia'). Já a argila possuiu $17 \%$ de fração argila, $77 \%$ de fração silte e $6 \%$ de fração areia. A maior fração de partículas finas na argila $(<2 \mu \mathrm{m})$ foi devido à presença de argilominerais [5]. A diferença entre o tamanho de partículas da argila e do resíduo pode levar a melhor empacotamento no corpo de prova à verde, pois as partículas menores tendem a preencher os vazios entre as partículas maiores, o que pode resultar em compacto verde com maior resistência mecânica, importante para evitar trincas durante a extração ou no manuseio anterior à queima.

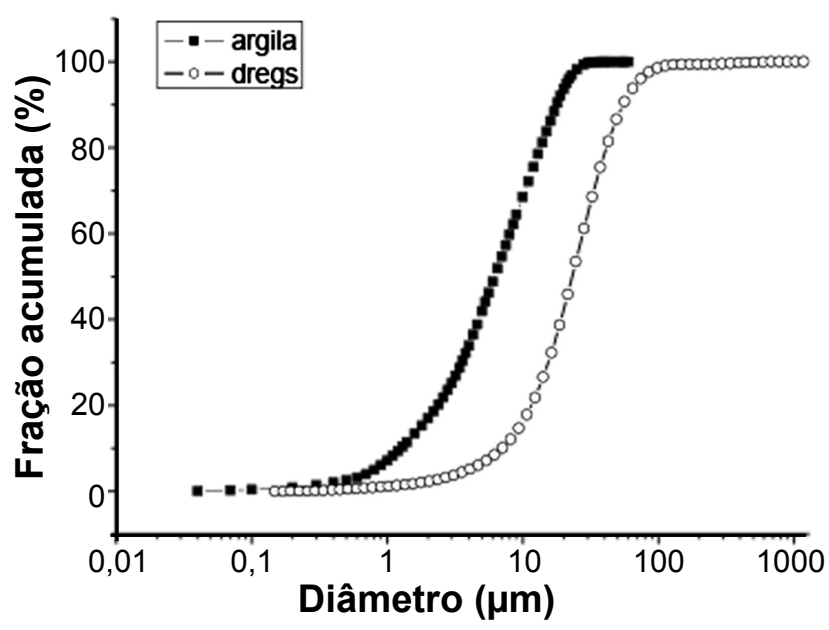

Figura 3: Curvas de distribuição de tamanho de partículas das matérias-primas.

[Figure 3: Particle size distribution curves of raw materials.]

O comportamento térmico das matérias-primas pode ser observado na Fig. 4. A curva de TG da argila mostrou uma perda de massa em torno de $2 \%$ entre 20 e $200{ }^{\circ} \mathrm{C}$, causada pela evaporação da água adsorvida fisicamente. Próximo a $280{ }^{\circ} \mathrm{C}$ notou-se um pico exotérmico de baixa intensidade, acompanhado de perda de massa em torno de $1 \%$, o qual foi associado à decomposição da matéria orgânica. Em $528,1^{\circ} \mathrm{C}$ foi observado um evento endotérmico, associado à perda de massa de cerca de $9 \%$. Esse pico foi relacionado à desidroxilação da caulinita $\left(\mathrm{Al}_{2} \mathrm{O}_{3} \cdot 2 \mathrm{SiO}_{2} \cdot 2 \mathrm{H}_{2} \mathrm{O}\right)$ e formação da metacaulinita $\left(\mathrm{Al}_{2} \mathrm{O}_{3} \cdot 2 \mathrm{SiO}_{2}\right)$, uma fase amorfa [17]. O pico exotérmico, sem alteração de massa, em torno de 940 ${ }^{\circ} \mathrm{C}$ correspondeu ao início da decomposição da metacaulinita e formação de um espinélio $\mathrm{Al}-\mathrm{Si}\left(2 \mathrm{Al}_{2} \mathrm{O}_{3} \cdot 3 \mathrm{SiO}_{2}\right)$, com ordenação de curto alcance [18]. A análise térmica do dregs apresentou um pico exotérmico a $527,9{ }^{\circ} \mathrm{C}$, o qual foi acompanhado de uma perda de massa em torno de $12 \%$. Esse pico foi relativo à decomposição da lignina, que ocorre próximo a $530{ }^{\circ} \mathrm{C}$ [19]. Uma perda de massa mais significativa próximo a $25 \%$ foi associada ao pico endotérmico que ocorreu em $809^{\circ} \mathrm{C}$, o qual foi relacionado à decomposição da calcita [1], que ocorreu segundo a reação:

$$
\mathrm{CaCO}_{3(\mathrm{~s})}+\text { energia } \rightarrow \mathrm{CaO}_{(\mathrm{s})}+\mathrm{CO}_{2(\mathrm{~g})}
$$

Na Tabela II são mostrados os limites de Atterberg e
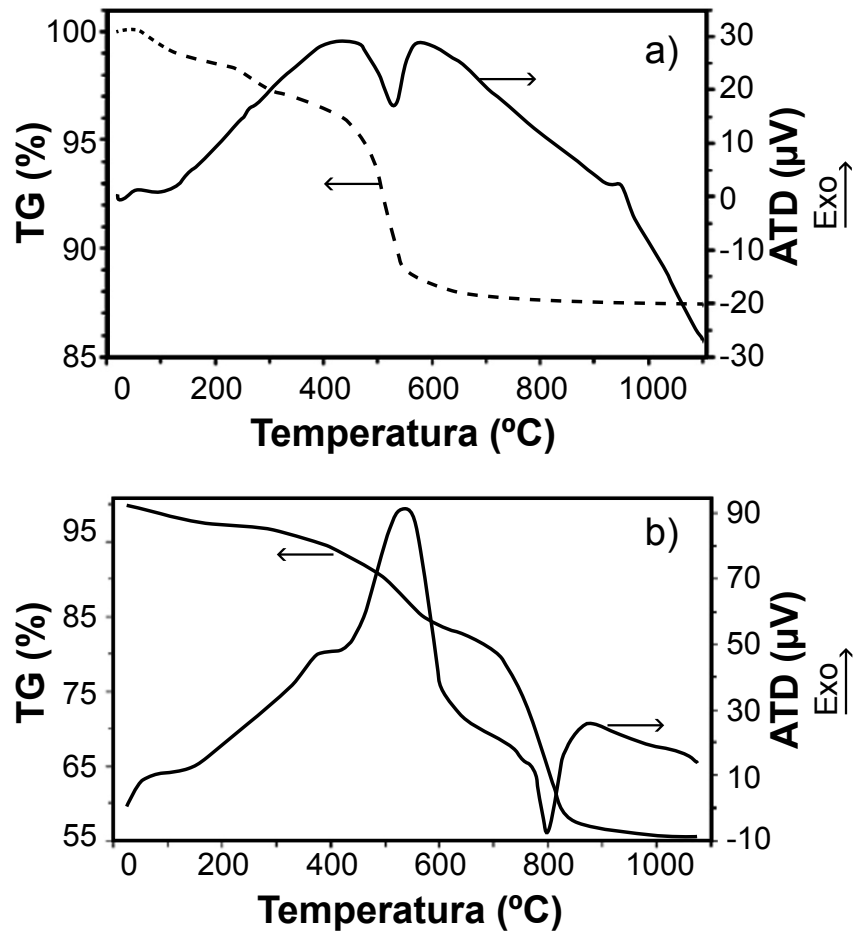

Figura 4: Curvas de análise térmica diferencial e termogravimétrica das matérias-primas: a) argila; e b) resíduo.

[Figure 4: Differential thermal analysis and thermogravimetry curves of raw materials: a) clay; and b) waste.]

índice de plasticidade (IP) das misturas.É importante avaliar a plasticidade das massas dado que a secagem das peças é dificultada com o aumento do limite de plasticidade (LP), porém alta plasticidade normalmente melhora a resistência mecânica, além de reduzir o desgaste dos equipamentos de conformação [14]. Fatores tais como composição mineralógica, distribuição de tamanho de partículas, matéria orgânica e aditivos podem afetar a plasticidade das argilas [20]. Fina granulometria e presença de matéria orgânica tendem a aumentar a plasticidade das massas argilosas; já a presença de sílica livre na forma de quartzo e resíduos não plásticos reduzem a plasticidade da massa. A argila utilizada foi considerada de alta plasticidade, por possuir IP $>15$ [21]. Inicialmente o LP tendeu a cair com o percentual de resíduo, já com 30 e $40 \%$ de dregs o valor aumentou. Apesar de o dregs ser considerado não plástico, o $\mathrm{CaCO}_{3}$, seu principal componente, é higroscópico, assim em percentuais acima de $30 \%$ a absorção de água do dregs pode ter sido responsável por elevar o LP, que é uma medida de umidade. A incorporação do dregs também influenciou no limite de liquidez (LL), que foi inferior em todas as formulações ao da argila pura, levando à redução no IP com aumento do teor de dregs. Esse comportamento foi devido à composição de referência, sem adição de dregs, ter maior percentual de argilomineral, como pode ser inferido pelos resultados da análise química (Tabela I) e mineralógica (Fig. 2a) da argila, o que elevou o IP dessa formulação.

As fases cristalinas identificadas por DRX em todas formulações após queima (Fig. 5) foram hematita e quartzo. A presença de quartzo mostrou que parte desse composto 
Tabela II - Limites de Atterberg (LP - limite de plasticidade; LL - limite de liquidez) e índice de plasticidade (IP) das misturas.

[Table II - Atterberg limits (LP - plastic limit; LL - liquid limit) and plastic index (IP) of mixtures.]

\begin{tabular}{cccc}
\hline $\begin{array}{c}\text { Fração de dregs } \\
\text { \% em massa })\end{array}$ & $\begin{array}{c}\text { LP } \\
(\%)\end{array}$ & $\begin{array}{c}\text { LL } \\
(\%)\end{array}$ & $\begin{array}{c}\text { IP } \\
(\%)\end{array}$ \\
\hline 0 & 36 & 66 & 30 \\
10 & 35 & 54 & 19 \\
20 & 33 & 57 & 24 \\
30 & 35 & 56 & 21 \\
40 & 37 & 52 & 15 \\
\hline
\end{tabular}

não reagiu com os demais componentes da massa. Já a hematita, possivelmente formada pela mudança no estado de oxidação do $\mathrm{Fe}$ durante a sinterização, foi responsável pela cor avermelhada do produto. Verificou-se que não apareceram picos relativos à caulinita presente na argila, estando de acordo com a análise térmica (Fig. 4a), onde foi indicado que a decomposição da caulinita e formação de metacaulinita ocorreu em torno de $500{ }^{\circ} \mathrm{C}$. Nos corpos de prova sinterizados a $850{ }^{\circ} \mathrm{C}$, observou-se que parte do carbonato proveniente do dregs não foi calcinada, tendo sido identificada a fase calcita nos difratogramas. Notou-se também que a incorporação de dregs à argila levou à formação de gehlenita. Por ser formada pela reação da metacaulinita com o $\mathrm{CaO}$ [17], a obtenção de gehlenita $\left(\mathrm{Ca}_{2} \mathrm{Al}_{2} \mathrm{SiO}_{7}\right)$ nos CPs sinterizados foi favorecida com o aumento de percentual de cálcio na mistura. Apesar de ser considerada uma fase metaestável, pois poderia reagir com o $\mathrm{SiO}_{2}$ formando wollastonita $\left(\mathrm{CaSiO}_{3}\right)$ e anortita $\left(\mathrm{CaAl}_{2} \mathrm{Si}_{2} \mathrm{O}_{8}\right)$, a presença de gehlenita em amostras carbonatadas foi relacionada à elevada concentração de $\mathrm{CaO}$, que originou zonas ricas em cálcio, tornando possível a estabilização da gehlenita [22]. A formação de fases cristalinas ricas em cálcio mostrou que parte do $\mathrm{CaO}$ originado do resíduo foi estabilizado. Caso o $\mathrm{CaO}$ permanecesse não reagido na cerâmica, seria facilmente hidratado na presença de umidade formando $\mathrm{Ca}(\mathrm{OH})_{2}$ (portlandita), que poderia causar trincas na peça [23]. De acordo com os difratogramas, a intensidade dos picos da gehlenita também foi maior quando a sinterização dos CPs foi feita a $950{ }^{\circ} \mathrm{C}$, sugerindo que a temperatura auxiliou na reação no estado sólido entre a metacaulinita e o $\mathrm{CaO}$ e estabilização desse óxido na cerâmica. Nesta temperatura também houve formação de anortita. Como o dregs apresentou teor significativo de $\mathrm{Na}_{2} \mathrm{O}$ em torno de $8 \%$, também houve a formação de aluminossilicatos de sódio, como albita $\left(\mathrm{NaAlSi}_{3} \mathrm{O}_{8}\right)$ e nefelina $\left(\mathrm{NaAlSiO}_{4}\right)$. Assim como a gehlenita, essas fases cristalinas conferem boa resistência mecânica à cerâmica estrutural [7].

As propriedades físico-mecânicas dos corpos de prova sinterizados em 850 e $950^{\circ} \mathrm{C}$ são apresentadas nas Figs. 6 e 7. Uma das formas de mensurar a efetividade do processo de sinterização é por meio da retração linear de queima (RLQ), sendo a maior retração indicativo de maior densificação.



Figura 5: Difratogramas de raios $\mathrm{X}$ dos corpos de prova sinterizados a: a) $850{ }^{\circ} \mathrm{C}$; e b) $950{ }^{\circ} \mathrm{C}$.

[Figure 5: X-ray diffraction patterns of specimens sintered at: a) $850{ }^{\circ} \mathrm{C}$; and b) $950^{\circ} \mathrm{C}$.]

A RLQ (Fig. 6) também é um parâmetro importante para garantir a qualidade dos produtos cerâmicos, já que excessiva retração pode causar deformações das peças durante a queima [17] ou criar tensões acima da resistência do material, levando à formação e propagação de trincas. Para as composições sinterizadas a $950{ }^{\circ} \mathrm{C}$, houve aumento na RLQ com adições de até $20 \%$ de dregs. Este comportamento pode ter sido ocasionado pela presença de maior percentual de óxidos fundentes, tais como $\mathrm{CaO}, \mathrm{Na}_{2} \mathrm{O}$ e $\mathrm{MgO}$, nas massas com dregs, que favoreceram o processo de sinterização. Entretanto, nas formulações com mais de $30 \%$ de dregs a RLQ caiu em consequência da concentração de $\mathrm{CaCO}_{3}$ do resíduo, que se decompõe liberando $\mathrm{CO}_{2}$, cuja

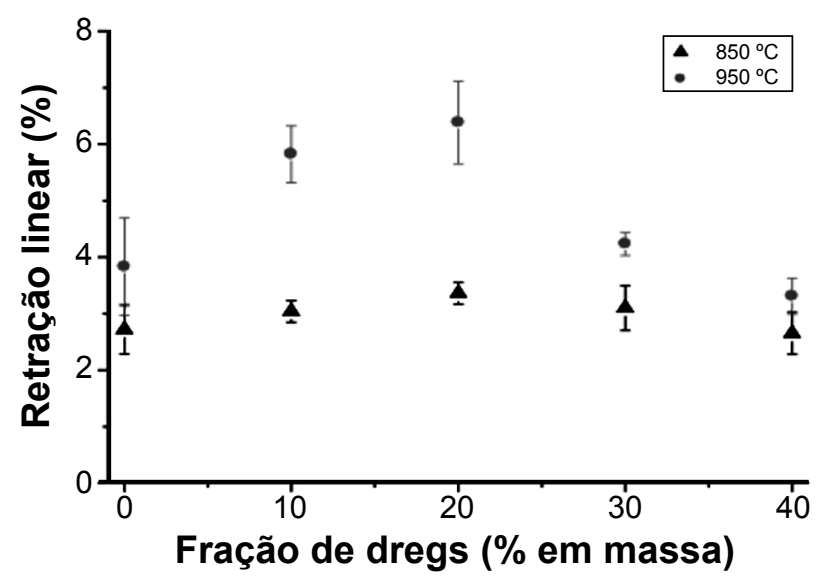

Figura 6: Retração linear de queima em função do percentual de resíduo e temperatura de queima.

[Figure 6: Linear shrinkage as a function of waste content and firing temperature.] 
pressão pode ter compensado parte do efeito da aproximação das partículas durante a queima. Contudo, a RLQ dos CPs sinterizados a $850{ }^{\circ} \mathrm{C}$ sofreu menos influência do percentual de dregs, devido à calcinação incompleta do $\mathrm{CaCO}_{3}$ na massa cerâmica nessa temperatura, como constatado na análise mineralógica dos corpos de prova, além de a sinterização ser governada por mecanismos de difusão no estado sólido abaixo de $950{ }^{\circ} \mathrm{C}$ [13], que causou menor retração.

A absorção de água (AA, Fig. 7a), considerada uma medida indireta da porosidade aparente (PA, Fig. 7b), é um fator fundamental para melhorar a durabilidade de peças cerâmicas, dado que quanto menor sua $\mathrm{AA}$, maior é a resistência a condições do ambiente externo [24]. Os valores de AA e PA aumentaram com o percentual de resíduo para queima realizada em $850{ }^{\circ} \mathrm{C}$; já em $950{ }^{\circ} \mathrm{C}$ a $\mathrm{AA}$ e a $\mathrm{PA}$ permaneceram constantes, dentro do desvio-padrão, até adições de $20 \%$ de dregs e cresceram com adição de maiores percentuais. Esse comportamento pode ter sido resultante da liberação de gases pela decomposição do $\mathrm{CaCO}_{3}$ do resíduo. A liberação de voláteis durante a sinterização também levou à redução na massa específica aparente (MEA, Fig. 7c), com a adição de dregs à argila nos dois ciclos de queima utilizados. Nota-se na Fig. 7d que a perda ao fogo (PF) aumentou com o teor de dregs, sendo maior com o aumento da temperatura, devido à perda de massa das matérias-primas não ocorrer totalmente até $850{ }^{\circ} \mathrm{C}$, como mostrado na análise térmica. Com o aumento da PF e redução na MEA inferiu-se que houve aumento também na porosidade total, dada pela soma da porosidade aberta e porosidade fechada. A maior PF foi verificada para a composição com $40 \%$ de dregs em queima a $950{ }^{\circ} \mathrm{C}$, o que justificou o fato de o aumento de temperatura não ter reduzido a AA e PA nesta formulação.

Com incorporação de 10 e $20 \%$ de dregs foi verificado aumento na resistência à flexão da argila (Fig. 8), em ambas temperaturas de sinterização, contudo esse efeito pôde ser melhor observado na queima a $950{ }^{\circ} \mathrm{C}$. Nesta temperatura a possível presença do mecanismo de sinterização com fase líquida [13], como indicado pelas imagens por MEV (Fig. 9), pode ter favorecido a consolidação dos $\mathrm{CPs}$, elevando a resistência. Entretanto, com incorporação de 30 e $40 \%$ de dregs ocorreu queda acentuada na resistência à flexão, de forma que a resistência ficou abaixo da referência $(0 \%$ dregs). Apesar de o dregs conter óxidos fundentes, que reduzem a refratariedade da argila e facilitam o processo de sinterização, quando adicionado em elevados percentuais, acima de $30 \%$, ocorreu aumento excessivo da porosidade total da peça, como indicado pelos valores de PA e MEA. Com o aumento da porosidade a resistência mecânica tende a cair, por ser prejudicada principalmente pela concentração de tensão nos poros, os quais ainda reduzem a área efeti-
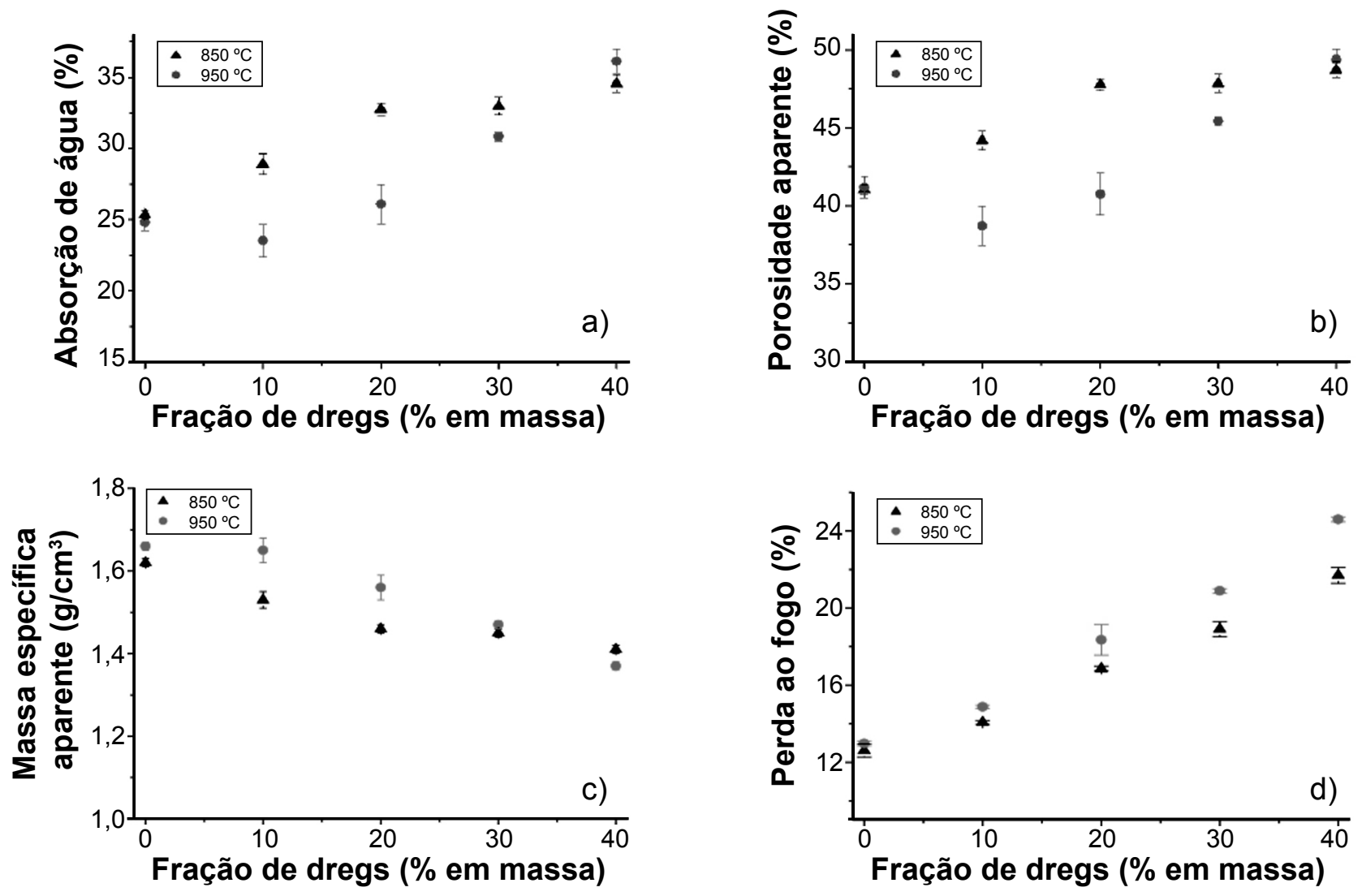

Figura 7: Absorção de água (a), porosidade aparente (b), massa específica aparente (c) e perda ao fogo (d) em função do percentual de resíduo e temperatura de queima.

[Figure 7: Water absorption (a), apparent porosity (b), apparent density (c), and loss on ignition (d) as a function of waste amount and firing temperature.] 


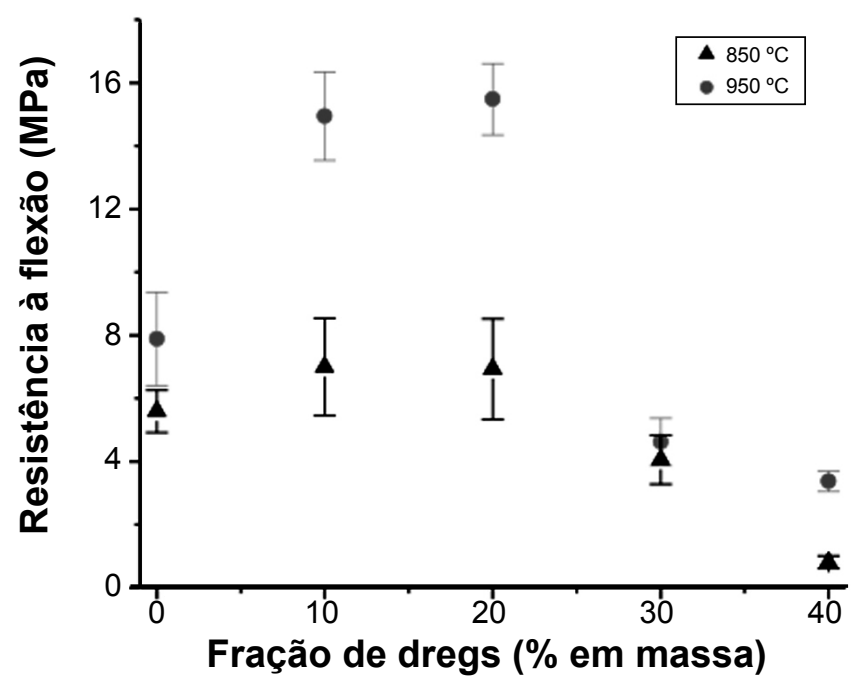

Figura 8: Resistência à flexão em função do percentual de resíduo e temperatura de queima.

[Figure 8: Bending strength as a function of waste amount and firing temperature.]
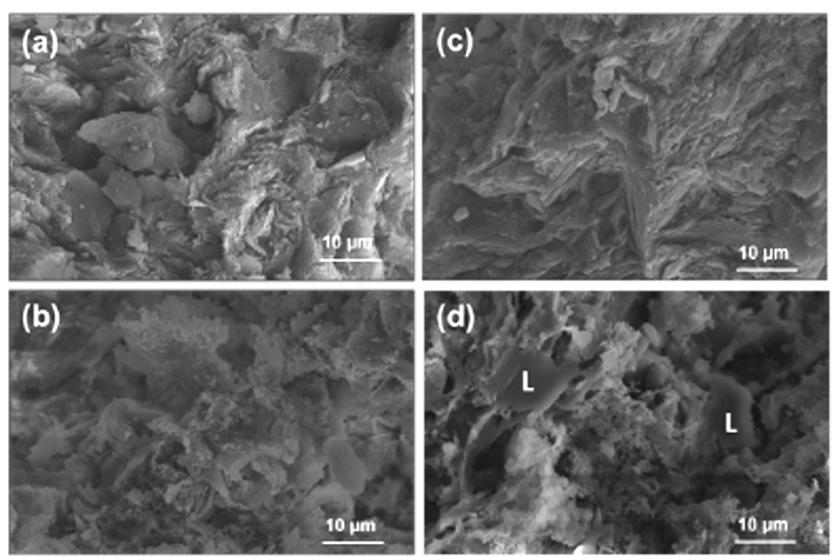

Figura 9: Micrografias de MEV da superfície de fratura dos corpos de prova sinterizados a $850{ }^{\circ} \mathrm{C}$ das composições com $0 \%$ de dregs (a) e com $20 \%$ de dregs (b) e a $950{ }^{\circ} \mathrm{C}$ das composições com $0 \%$ de dregs (c) e com $20 \%$ de dregs (d). L indica região de possível formação de fase líquida durante a sinterização.

[Figure 9: SEM micrographs of fracture surface of specimens sintered at $850{ }^{\circ} \mathrm{C}$ of compositions with $0 \%$ dregs (a) and $20 \%$ dregs (b), and at $950{ }^{\circ} \mathrm{C}$ with $0 \%$ dregs (c) and $20 \%$ dregs (d). $L$ indicates region of possible liquid phase formation during sintering.]

va de aplicação da carga. Além disso, como o dregs contém maior fração de partículas com granulometria superior a 20 $\mu \mathrm{m}$, o aumento no seu teor começa a ter influência negativa no empacotamento físico dos grãos, sendo prejudicial para a densificação e consequentemente na resistência mecânica. Além da interferência nas propriedades físico-mecânicas, os percentuais de 30 e $40 \%$ originaram CPs escurecidos, devido à coloração do resíduo. Assim, para aplicações industriais esses elevados percentuais também apresentariam limitações estéticas.

Na Fig. 9 são apresentadas as micrografias obtidas por MEV das formulações de referência e com $20 \%$ de dregs. As microestruturas das composições com queima em $850{ }^{\circ} \mathrm{C}$
(Figs. 9a e 9b) não apresentaram sinais de formação de fase líquida durante a sinterização. Notou-se apenas a presença de partículas aglomeradas indicando reação no estado sólido, além de poros com morfologia irregular, característicos do estágio inicial de sinterização [25]. Quando a sinterização foi realizada a $950{ }^{\circ} \mathrm{C}$, poucas alterações ocorreram na microestrutura (Figs. 9c e 9d), porém foi possível visualizar que em algumas regiões a textura foi mais lisa. Nesta temperatura também ficou mais evidente o aumento da porosidade com a incorporação de dregs, além de terem sido observadas algumas regiões com indícios de formação de fase líquida durante a sinterização no CP com $20 \%$ de dregs.

\section{CONCLUSÕES}

Os resultados mostraram que é possível a valorização do dregs como matéria-prima alternativa em cerâmica vermelha, limitando o percentual desse resíduo em $20 \%$ na massa. Essa substituição seria positiva do ponto de vista ambiental, pois reduziria a exploração da matéria-prima argilosa, bem como a disposição do resíduo em aterros. $\mathrm{O}$ uso do dregs em massas para cerâmica vermelha se mostrou benéfico à resistência à flexão para adições de até $20 \%$ em massa, tendo sido os melhores resultados apresentados pelos corpos de prova sinterizados em $950^{\circ} \mathrm{C}$. Contudo, por ser constituído essencialmente de $\mathrm{CaCO}_{3}$, sua presença na massa argilosa favoreceu o aumento da absorção de água, porosidade aparente e perda ao fogo, bem como queda na massa específica aparente. Observou-se pela análise mineralógica que nas composições com o resíduo houve formação de gehlenita e anortita, fases ricas em cálcio. Assim, a incorporação do dregs levou à formação de fases cristalinas que forneceram resistência ao material. Também foi observada a influência do resíduo na microestrutura dos corpos de prova sinterizados. As micrografias evidenciaram o aspecto rugoso da superfície de fratura dos corpos de prova, mostrando que em ambos ciclos de queima $\left(850\right.$ e $\left.950{ }^{\circ} \mathrm{C}\right)$ foi predominante o mecanismo de sinterização no estado sólido. Apenas na formulação com $20 \%$ de dregs, com queima em $950{ }^{\circ} \mathrm{C}$, foram verificados indícios de desenvolvimento de fase líquida durante a sinterização, justificando a melhor resistência mecânica dessa composição.

\section{AGRADECIMENTO}

À FAPES, pelo auxílio financeiro.

\section{REFERÊNCIAS}

[1] F.M. Martins, J.M. Martins, L.C. Ferracin, C.J. da Cunha, J. Hazard. Mater. 147 (2007) 610.

[2] K. Manskinen, H. Nurmesniemi, R. Pöykiöc, Chem. Eng. J. 166 (2011) 954.

[3] F. Cabral, H.M. Ribeiro, L. Hilário, L. Machado, E. Vasconcelos, Bioresour. Technol. 99 (2008) 8294.

[4] S.N. Monteiro, C.M.F. Vieira, Constr. Build. Mater. 68 (2014) 599. 
[5] B.C.A. Pinheiro, J.N.F. Holanda, J. Mater. Proc. Technol. 209 (2009) 5606.

[6] L.L. Izidio, G.W. Subtil, A.A. de Andrade, O Papel, Nota técn. jan. (2014) 50 .

[7] E. Wolff, W.K. Schwabe, S.V. Conceição, J. Clean. Prod. 96 (2015) 282.

[8] E. Wolff, W.K. Schwabe, S.V. Conceição, J.A. SantannaGreco, M. Greco, R.R. Machado, Clean Technol. Envir. 19 (2017) 379.

[9] Ass. Bras. Norm. Técn., NBR 6459, Solo - determinação do limite de liquidez, S. Paulo (1984).

[10] Ass. Bras. Norm. Técn., NBR 7180, Solo - determinação do limite de plasticidade, S. Paulo (1984).

[11] P.S. Santos, Ciência e tecnologia de argilas, $2^{\mathrm{a}}$ ed., 1, Edgard Blücher, S. Paulo (1989).

[12] C.M.F. Vieira, R.M. Pinheiro, Cerâmica 57 (2011) 319.

[13] F.A.C. Milheiro, M.N. Freire, A.G.P. Silva, J.N.F. Holanda, Ceram. Int. 31 (2005) 757.

[14] S.N. Monteiro, C.M.F. Vieira, Appl. Clay Sci. 27 (2004) 229.

[15] H. Nurmesniemi, R. Pöykiö, P.Perämäki, T. Kuokkanen, Chemosphere 61 (2005) 1475.

[16] J.P.V.T. Manhães, J.M.S. Moreira, J.N.F. Holanda,
Cerâmica 55 (2009) 371.

[17] H. Baccour, M. Medhioub, F. Jamoussi, T. Mhiri, J. Mater. Proc. Technol. 209 (2009) 2812.

[18] R.A. Silva, S.R. Teixeira, A.E. Souza, D.I. Santos, M. Romero, J.Ma. Rincón, Appl. Clay Sci. 52 (2011) 165.

[19] S. Tsujiyama, A. Miyamori, Thermochim. Acta 351 (2000) 177.

[20] F.A. Andrade, H.A. Al-Qureshi, D. Hotza, Appl. Clay Sci. 51 (2011) 1.

[21] H.P. Caputo, Mecânica dos solos e suas aplicações, $6^{\mathrm{a}}$ ed., 1, LTC, Rio de Janeiro (2011).

[22] M.M. Jordán, T. Sanfeliu, C. de La Fuente, Appl. Clay Sci. 20 (2001) 87.

[23] G. Cultrone, E. Sebastián, K. Elert, M.J. de la Torre, O. Cazalla, C. Rodriguez-Navarro, J. Eur. Ceram. Soc. 24 (2004) 547.

[24] D. Eliche-Quesada, C. Martínez-García, M.L. MartínezCartas, M.T. Cotes-Palomino, L. Pérez-Villarejo, N. CruzPérez, F.A. Corpas-Iglesias, Appl. Clay Sci. 52 (2011) 270. [25] B.C.A. Pinheiro, J.N.F. Holanda, Cerâmica 56 (2010) 237.

(Rec.26/01/2018, Rev. 13/04/2018, 08/09/2018, 29/10/2018, Ac. 31/10/2018) 